\title{
Synthesis of the C8'-epimeric thymine pyranosyl amino acid core of amipurimycin
}

\author{
Pramod R. Markad, Navanath Kumbhar and Dilip D. Dhavale *
}

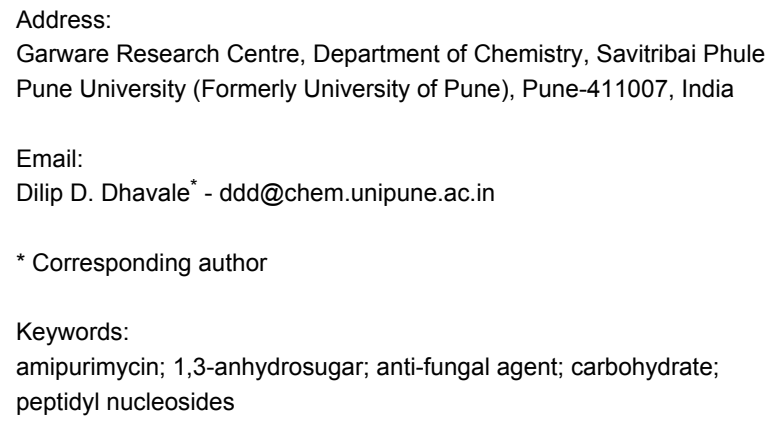

\author{
Beilstein J. Org. Chem. 2016, 12, 1765-1771. \\ doi:10.3762/bjoc. 12.165 \\ Received: 28 May 2016 \\ Accepted: 18 July 2016 \\ Published: 05 August 2016 \\ Associate Editor: D. Y.-K. Chen \\ (c) 2016 Markad et al.; licensee Beilstein-Institut. \\ License and terms: see end of document.
}

\begin{abstract}
The C8'-epimeric pyranosyl amino acid core $\mathbf{2}$ of amipurimycin was synthesized from D-glucose derived alcohol $\mathbf{3}$ in 13 steps and $14 \%$ overall yield. Thus, the Sharpless asymmetric epoxidation of allyl alcohol 7 followed by trimethyl borate mediated regioselective oxirane ring opening with azide, afforded azido diol 10. The acid-catalyzed 1,2-acetonide ring opening in 10 concomitantly led to the formation of the pyranose ring skeleton to give 2,7-dioxabicyclo[3.2.1] octane 12. Functional group manipulation in 12 gave 21 that on stereoselective $\beta$-glycosylation afforded the pyranosyl thymine nucleoside $\mathbf{2}$ - a core of amipurimycin.
\end{abstract}

\section{Introduction}

Peptidyl nucleoside antibiotics are a class of complex molecules that encompass an extensive array of natural products [1]. The notable structural features of peptidyl nucleosides are responsible for their miscellaneous biological activities such as antitumor, antiviral, antibacterial and antifungal [2]. Peptidyl nucleosides in which the sugar part is in the furanose form are common, however, the sugar framework in the pyranose form, with a nucleobase and a peptide linker at either ends, are rare in nature. A few examples of this category are amipurimycin and miharamycin that are known as antifungal agents [2]. Amipurimycin (1) isolated from Streptomyces novoguineensis sp. nov., displays antifungal activity against pyricularia oryzae - a causative agent in rice blast disease [3,4]. Goto and co-workers have proposed the primary structure of amipurimycin (1, Figure 1) that involves (a) a unique pyranosyl amino acid ring skeleton with a hydroxy group and a branched 1,2-dihydroxyethyl side chain at C3', (b) a glycosidic $\beta$-linked purine nucleobase, and (c) a five-membered cis-pentacin framework coupled to C6' via the $\mathrm{N}$-terminus of an amino acid [5]. The absolute configurations at the C6', C2" and C3" of the cis-pentacin are still undefined. Thus, the partially unresolved structure, a potent antifungal activity, the unexplored mode of action and the limited synthetic study make amipurimycin (1) an attractive target for futher investigation. As of now, a total synthesis of $\mathbf{1}$ 
is not known. The reported methodologies are mainly focused on construction of the exigent central pyranosyl amino acid fragment with or without the C3'-branched chain and nucleobase, frequently using carbohydrate substrate [6-15]. In a noncarbohydrate approach, Garner and co-workers have exploited a cycloaddition pathway between a poly-oxygenated diene and Garner's aldehyde for constructing the carbohydrate core of amipurimycin [9]. Recently, Datta and co-workers reported the first synthesis of a fully-functionalized thymine analogue of amipurimycin, utilizing D-serine as a starting material [6]. In this regard, our group has recently reported the synthesis of the C3'-branched carbohydrate core of amipurimycin starting from D-glucose [15]. In the continuation of this area, we now report the synthesis of the amipurimycin pyranose core comprising of (a) a hydroxy and 1,2-dihydroxyethyl side chain at C3' having a C8' epimeric center, (b) an C5' amino acid pendant and (c) the thymine nucleobase (2). Our results in this regard are described herein.

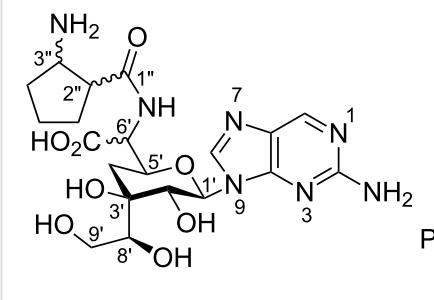

amipurimycin (1)

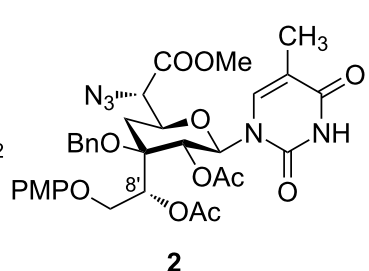

2
Figure 1: Antifungal antibiotic amipurimycin (1)

\section{Result and Discussion}

As shown in retrosynthetic analysis (Scheme 1), we envisioned that the substituted 2,7-dioxabicyclo[3.2.1] octane A could be glycosylated stereoselectively with the requisite nucleobase to give $\beta$-nucleoside pyranosyl skeleton $\mathbf{2}$. The bridged bicyclic system $\mathbf{A}$ was visualized from the azido diol $\mathbf{B}$. Thus, hydrolysis of the 1,2-acetonide functionality in $\mathbf{B}$ will lead to in situ generation of oxocarbenium ion at $\mathrm{C} 1$ to which concomitant addition of a hydroxy group (present in the side chain at C3) will give the requisite pyranose ring skeleton. Intermediate $\mathbf{B}$ could be derived from the allyl alcohol $\mathbf{C}$ by using the Sharpless asymmetric epoxidation followed by regioselective epoxide ring opening with an azide nucleophile. The synthesis of allyl alcohol $\mathbf{C}$ from D-glucose was reported by us earlier.

Our synthesis started with the homoallyl alcohol $\mathbf{3}$ (with defined ' $R$ ' absolute configuration at the $\mathrm{C} 3$-quaternary center) that is obtained from D-glucose as reported earlier by us in $37 \%$ overall yield [15] (Scheme 2). Selective protection of the C5 primary hydroxy group as PMP ether using $p$-methoxyphenol under Mitsunobu reaction conditions afforded 4 that on benzy-

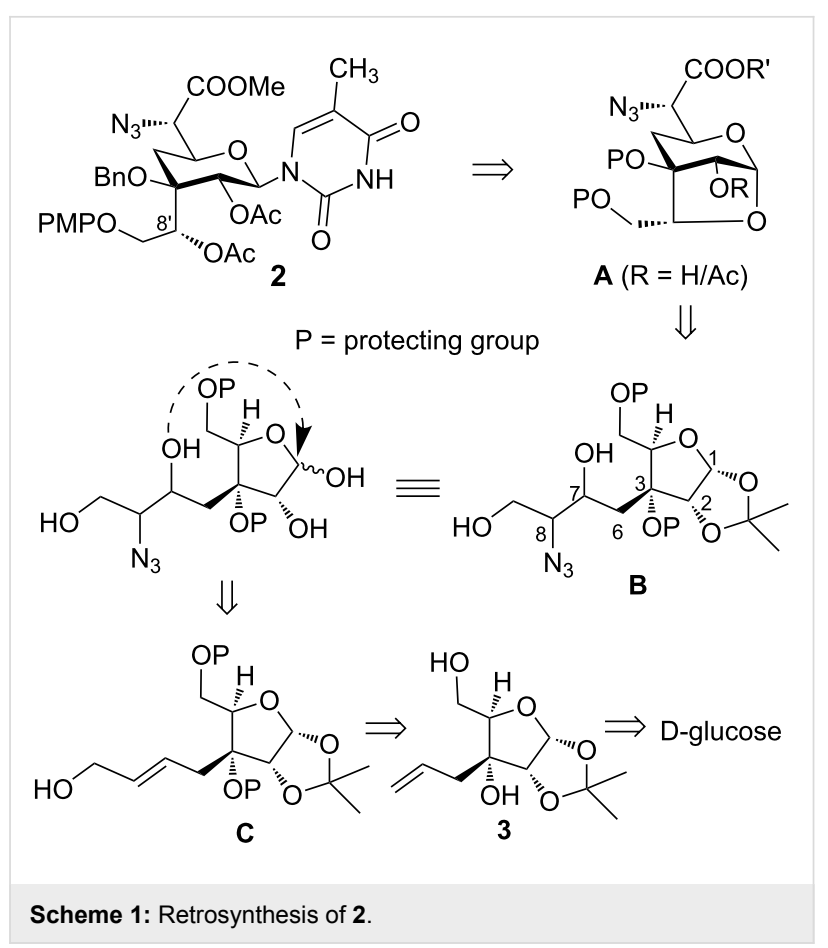

lation of the $\mathrm{C} 3$ hydroxy group ( $\mathrm{NaH}$ and benzyl bromide in DMF) gave compound 5. Upjohn dihydroxylation of 5 using $\mathrm{K}_{2} \mathrm{OsO}_{4} \cdot 2 \mathrm{H}_{2} \mathrm{O}$ followed by oxidative cleavage of diol with silica-supported $\mathrm{NaIO}_{4}$ gave aldehyde that was directly reacted with ethyl 2-(triphenylphosphoranylidene)acetate to give $\alpha, \beta$ unsaturated ester $6(E / Z=92: 8)$ in $83 \%$ yield over three steps. Reduction of ester 6 ( $E$-isomer) with DIBAL-H gave allyl alcohol 7 - a synthone for the Sharpless asymmetric epoxidation (SAE) $[16,17]$.

Thus, allyl alcohol 7 was subjected for SAE first using (+)-DET that afforded a diastereomeric mixture of epoxy alcohols $\mathbf{8}$ and 9 in the ratio of 88:12 (based on the ${ }^{1} \mathrm{H}$ NMR analysis) in $85 \%$ yield. Similarly, use of (-)-DET in SAE afforded epoxide 8 and 9 in the ratio of 18:82 in 83\% yield. With the understanding of SAE mnemonic, we assigned the absolute configuration in epoxide $\mathbf{8}$ as $7 S, 8 S$ and in epoxide $\mathbf{9}$ as $7 R, 8 R$. Subsequently, major isomers of epoxy alcohols $\mathbf{8}$ and $\mathbf{9}$ were individually subjected to regioselective epoxide ring opening using trimethyl borate and $\mathrm{NaN}_{3}$ in DMF that afforded azido diol $\mathbf{1 0}$ and $\mathbf{1 1}$ as major isomers, respectively $[18,19]$. In the next step, individual hydrolysis of the 1,2-acetonide group in $\mathbf{1 0}$ and $\mathbf{1 1}$ using TFA- $\mathrm{H}_{2} \mathrm{O}$ (3:1) provided the corresponding 1,3-anhydrosugar $\mathbf{1 2}$ and $\mathbf{1 3}$ in good yield.

The formation of 1,3-anhydrosugar 12/13 could be explained as follows (Scheme 3). Thus, treatment of 10/11 with TFA- $\mathrm{H}_{2} \mathrm{O}$ resulted in the opening of the 1,2-acetonide functionality and generation of an oxocarbenium ion Y. Intermolecular and re- 


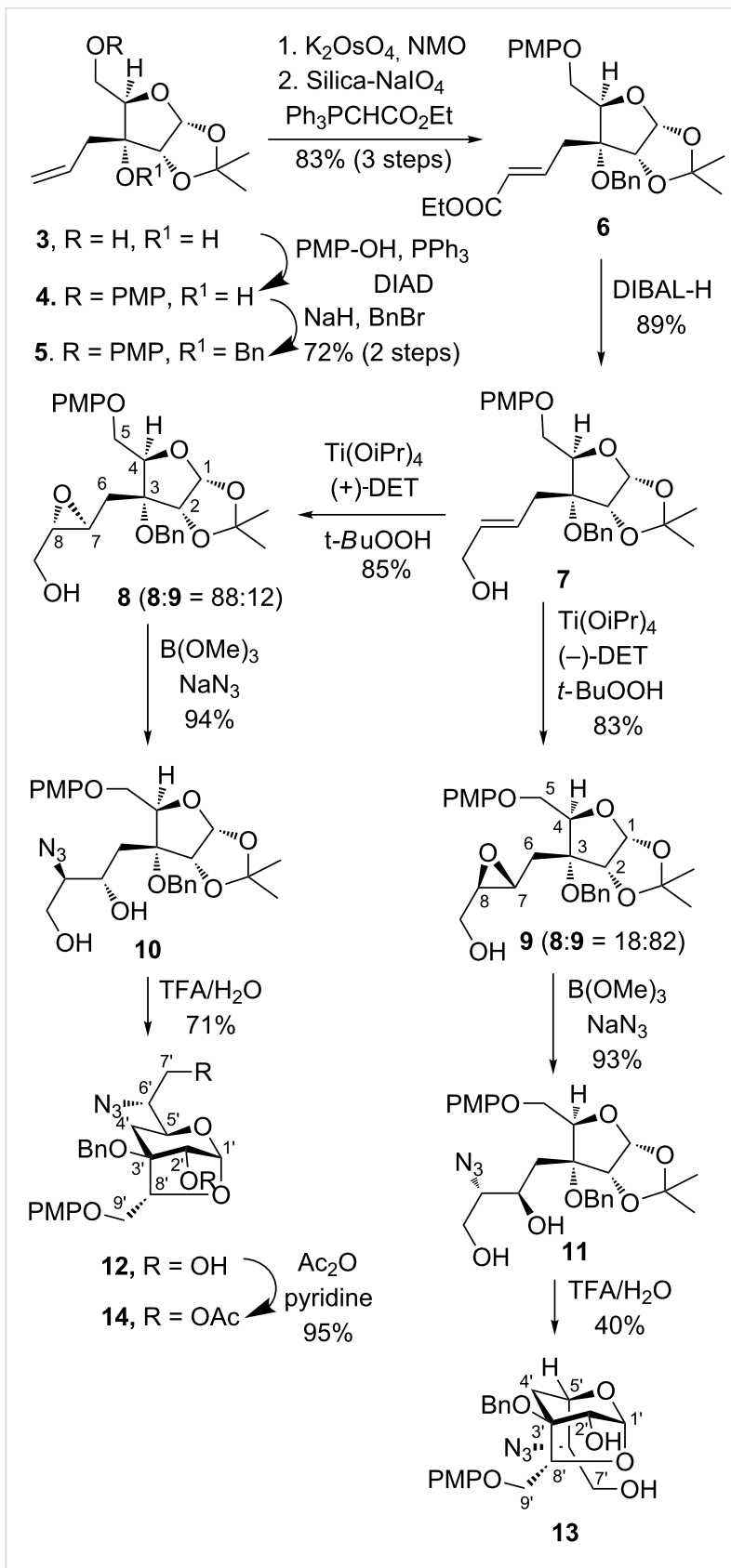

Scheme 2: Synthesis of 1,3-anhydrosugar 12 and 13.

versible addition of water would lead to hemiacetal $\mathbf{Z}$, however, intramolecular and irreversible attack of the secondary hydroxy group to the oxocarbenium ion $\mathbf{Y}$ led to a stable six-membered pyranose ring compound thus shifting the equilibrium in favour of bridged bicyclic system 12/13.

In order to validate the configurational assignments at the newly generated stereocenters, the coupling constants of protons at $\mathrm{C}^{\prime}$ ' and $\mathrm{C}^{\prime}$ ' in the pyranose ring of $\mathbf{1 2 / 1 3}$ are noticed to be decisive. In compound $\mathbf{1 2}$, both the $\mathrm{C} 4$ ' methylene protons were found to be merged and appeared as a multiplet at

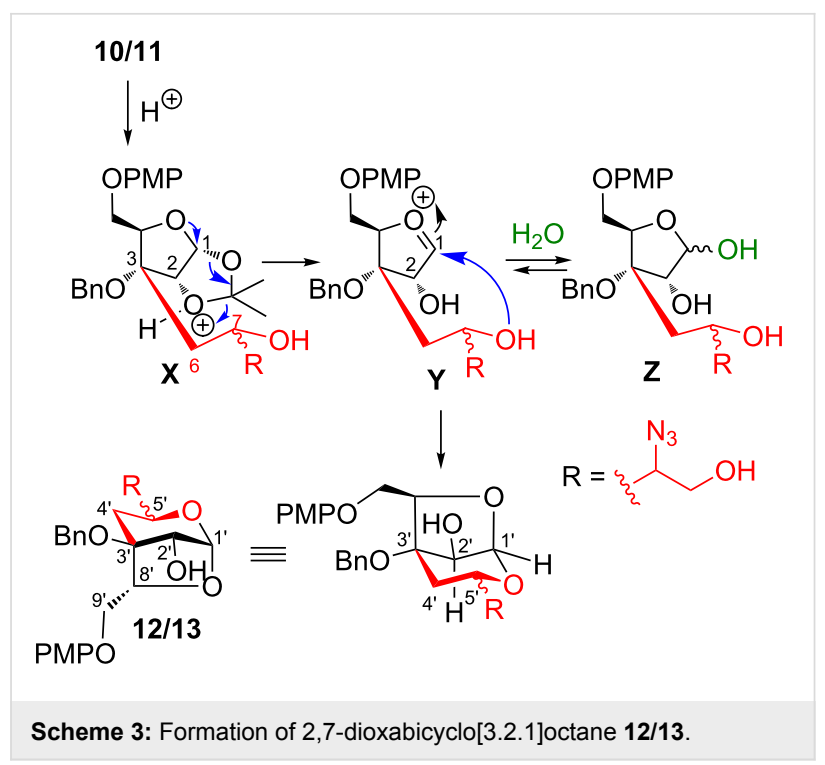

$\delta 2.10-2.16 \mathrm{ppm}$. Therefore, we converted 12 into its acetyl derivative 14 that allowed us to predict the absolute configuration at the newly generated stereocenters at C5' and C6' (corresponding to the $\mathrm{C} 7$ and $\mathrm{C} 8$ of epoxide 8) [20]. In the ${ }^{1} \mathrm{H}$ NMR of 14, appearance of a triplet at $\delta 2.30(J=12.7 \mathrm{~Hz})$ and a doublet of doublet at $\delta 2.09(J=12.7$ and $4.7 \mathrm{~Hz})$, integrating for one proton each, were assigned to the methylene protons at C4'. Based on the coupling constant and nOe studies (Figure 2), the signal at $\delta 2.30$ was assigned to the axially oriented proton at $\mathrm{C} 4$ '. As this proton appeared as a triplet with a large coupling constant of $12.7 \mathrm{~Hz}$ (vicinal and geminal), the adjacent C5' proton therefore assigned axial orientation indicating 5' $S$ absolute configuration as anticipated from the SAE mnemonic in compound 8. As the $\mathrm{C}^{\prime}$ ' and C6' stereocenters in $\mathbf{1 4}$ are derived from the regioselective $\mathrm{S}_{\mathrm{N}} 2$ opening of epoxide 8 by $\mathrm{NaN}_{3}$, the configuration at the C6' (carrying azido group) was therefore assigned as $6^{\prime} R$.

In the ${ }^{1} \mathrm{H}$ NMR spectrum of anhydrosugar 13, both the $\mathrm{C} 4$ ' protons appeared as two doublets of doublets at $\delta 2.47$ $(J=14.1$ and $8.3 \mathrm{~Hz})$ and $\delta 2.34(J=14.2$ and $7.4 \mathrm{~Hz})$. The vicinal coupling constants of 8.3 and $7.4 \mathrm{~Hz}$ between the $\mathrm{C} 4$ ' and $\mathrm{C} 5$ ' proton suggested distortion in the conformation of the six-membered ring of the bridged system. Since we have assigned the $\left(5^{\prime} S\right)$ configuration at $\mathrm{C}^{\prime}$ ' in $\mathbf{1 2}$, the anhydrosugar 13 expected to have the opposite- 5 ' $R$ configuration. Considering this fact, the alkyl pendant (azidoethanol group) in $\mathbf{1 3}$ is assumed to be axially oriented. However, this spatial arrangement gives rise to strong steric interactions between the alkyl pendant and C8' aryloxymethylene group (Figure 2). In order to avoid this strong repulsive interaction, compound $\mathbf{1 3}$ adopts relatively more stable twist-boat conformation as shown in Figure 2. The adoption of the twist-boat conformation gener- 


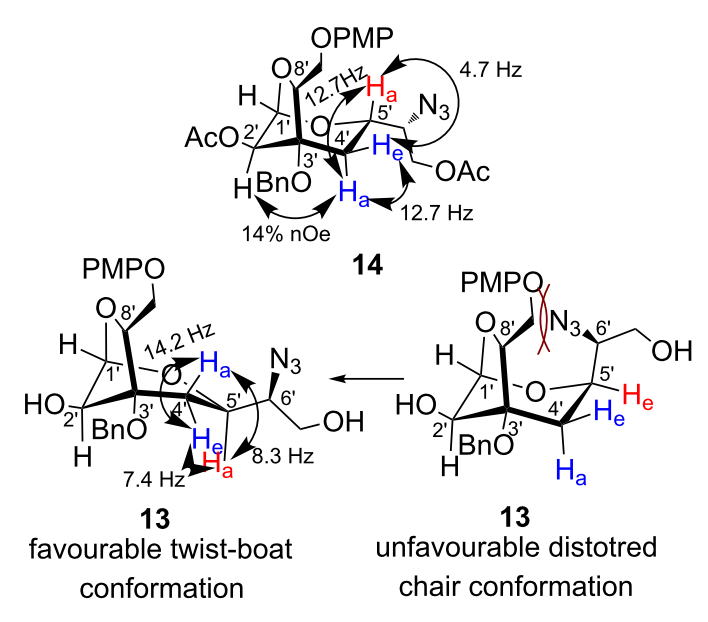

Figure 2: Conformational analysis of 13 and 14.

ates dihedral angles between the $\mathrm{H} 5^{\prime}$ and $\mathrm{H} 4$ 'a/H4'e as $\approx 150 \%$ $25^{\circ}$. This justifies the observed coupling constants in the ${ }^{1} \mathrm{H}$ NMR between $\mathrm{H} 5$ ' and $\mathrm{H} 4$ ' $\left(J_{\mathrm{H} 4}\right.$ 'a, $\mathrm{H} 5$ 'a $=8.3 \mathrm{~Hz}$ and

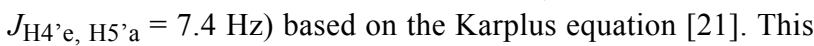
observation also confirms the assigned configurations as 5 ' $R$ and 6' $S$ in $\mathbf{1 3}$.

The experimental results on conformational preferences of $\mathbf{1 2}$ and $\mathbf{1 3}$ were corroborated using geometry-optimized density functional theory (DFT). The geometrically optimized preferred conformations of $\mathbf{1 2}$ and $\mathbf{1 3}$ are depicted in Figure 3, and geometrical parameters for torsion angles and intramolecular hydrogen bonding interactions are given in Table 1. As shown in Figure 3, the preferred conformation of $\mathbf{1 2}$ was found to be a stable distorted chair conformation (a). The significant hydrogen bonding interactions between ring oxygen $\mathrm{O}^{5}$ ' with $\mathrm{H} 7$ ' and $\mathrm{O} 7$ ' with $\mathrm{H} 5$ ' $a$ are accountable for preserving the stable ${ }^{4} C_{1}$ chair conformation of compound $\mathbf{1 2}$ by maintaining the values $159.77^{\circ} / 42.86^{\circ}$ for the $\theta\left(\mathrm{H} 4^{\prime} \mathrm{a}-\mathrm{C} 4^{\prime}-\mathrm{C} 5^{\prime}-\mathrm{H} 5\right.$ ' a) and $\varphi($ H4'e-C4'-C5'-H5'a) torsion angles (Table 1). Similarly, for compound 13 the preferred conformation was observed to be a twist-boat conformation (Figure 3b). The intramolecular interactions and hydrogen bonding provided additional stability to maintain the twist-boat conformation of $\mathbf{1 3}$ (Figure 3) and to adopt the dihedral angles of $143.94^{\circ} / 27.32^{\circ}$ between H5'a and H4'a/H4'e, respectively. This supports our earlier assignments made using ${ }^{1} \mathrm{H}$ NMR studies.

After confirming the absolute configurations of newly generated stereocenters, we continued our synthesis with anhydrosugar 12 as its configurations are matching with that of target compound. Thus, TEMPO-mediated selective oxidation of the primary hydroxy group in $\mathbf{1 2}$ to acid functionality followed by esterification using diazomethane afforded azido methyl ester 15. Acetylation of $\mathbf{1 5}$ with acetic anhydride in pyridine gave acetate derivative $\mathbf{1 6}$ in $95 \%$ yield. Having fully functionalized intermediate $\mathbf{1 6}$ in hand, we thought to incorporate the purine nucleobase using Vorbrüggen conditions. Thus, reaction of glycosyl donor 16 with bis(trimethylsilyl)-2-( $N$-acetylamino)-6-
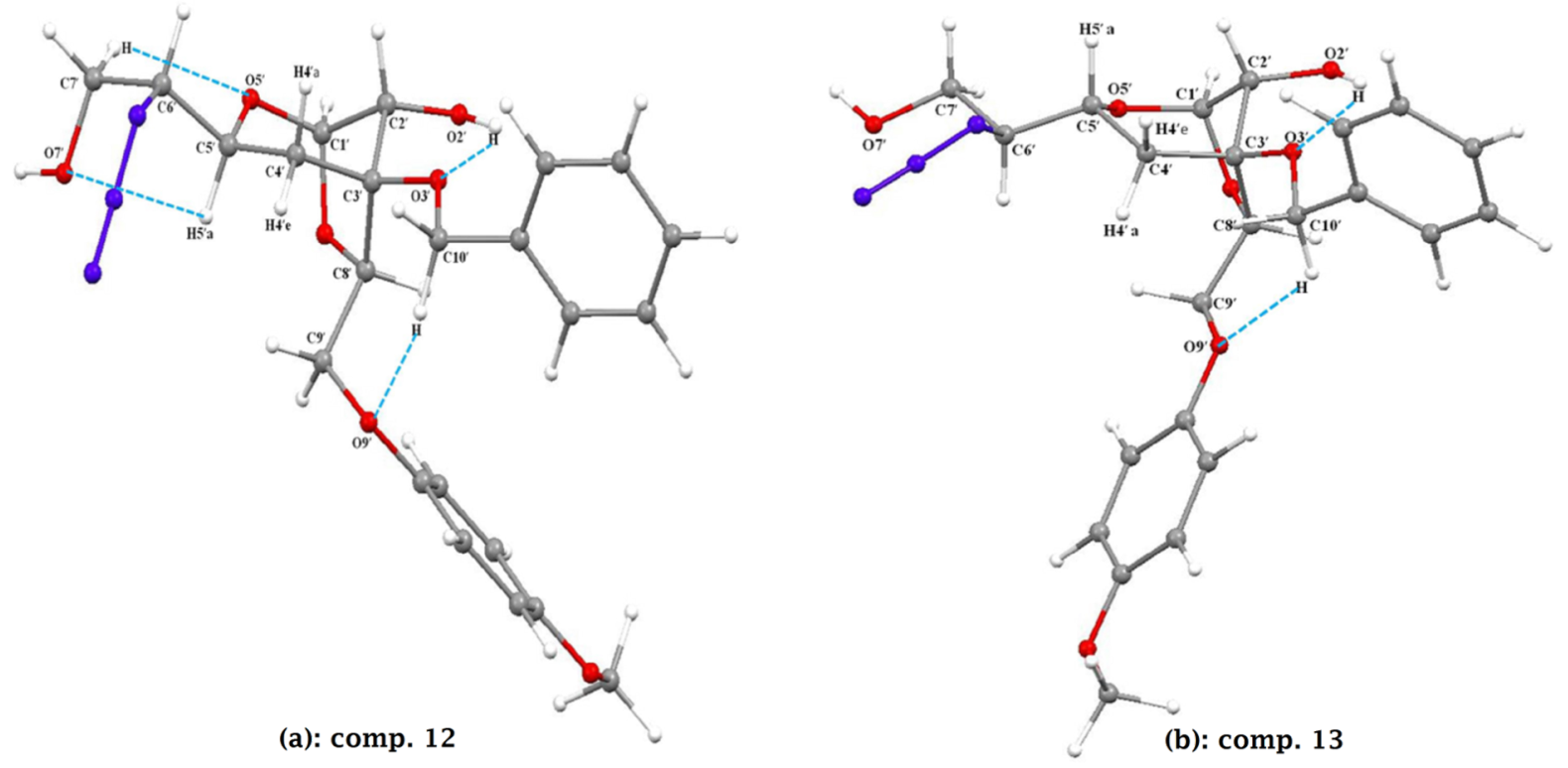

Figure 3: Geometrically optimized conformation of 12 and 13 respectively by DFT study. 
Table 1: Geometrical parameters for hydrogen bonding and torsion angles for 12 and 13.

\begin{tabular}{|c|c|c|c|c|c|}
\hline Comp. & Atoms involved in $\mathrm{H}$-bonds & Distance in $\AA$ & $\begin{array}{l}\text { Angle in } \\
\text { degree }\end{array}$ & Torsion angle values & $\begin{array}{l}\text { Energy in atomic units } \\
\text { (au) }\end{array}$ \\
\hline 12 & 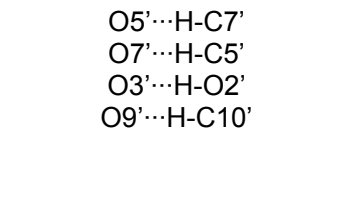 & $\begin{array}{l}2.480 \\
2.550 \\
2.190 \\
2.290\end{array}$ & $\begin{array}{c}98.74 \\
99.13 \\
112.34 \\
151.77\end{array}$ & $\begin{array}{l}\theta=H 4^{\prime} \mathrm{a}-\mathrm{C} 4^{\prime}-\mathrm{C5}^{\prime}-\mathrm{H} 5^{\prime} \\
a=200.23^{\circ} \\
(-159.77) \\
\Phi=\mathrm{H} 4^{\prime} \mathrm{e}-\mathrm{C} 4^{\prime}-\mathrm{C} 5^{\prime}-\mathrm{H} 5^{\prime} \\
a=317.14^{\circ} \\
(-42.86)\end{array}$ & -1583.424 au \\
\hline 13 & $\begin{array}{l}\mathrm{O} 5^{\prime} \cdots \mathrm{H}-\mathrm{C} 7^{\prime} \\
\mathrm{O} 3^{\prime} \cdots \mathrm{H}-\mathrm{O} 2^{\prime} \\
\mathrm{O} 9^{\prime} \cdots \mathrm{H}-\mathrm{C} 10^{\prime}\end{array}$ & $\begin{array}{l}2.426 \\
2.124 \\
2.372\end{array}$ & $\begin{array}{l}99.68 \\
114.39 \\
122.31\end{array}$ & $\begin{array}{l}\theta=H 4^{\prime} \mathrm{a}-\mathrm{C} 4-\mathrm{C} 5-\mathrm{H} 5^{\prime} \\
a=143.94^{\circ} \\
\varphi=\mathrm{H} 4^{\prime} \mathrm{e}-\mathrm{C} 4-\mathrm{C} 5-\mathrm{H} 5^{\prime} \\
\mathrm{a}=27.32^{\circ}\end{array}$ & $-1583.420 \mathrm{au}$ \\
\hline
\end{tabular}

chloropurine $\mathbf{1 7}$, under a variety of reaction conditions, of solvents, temperature, Lewis acids as well as the use of the thymine nucleobase 18 (Scheme 4) failed to provide the desired nucleoside.

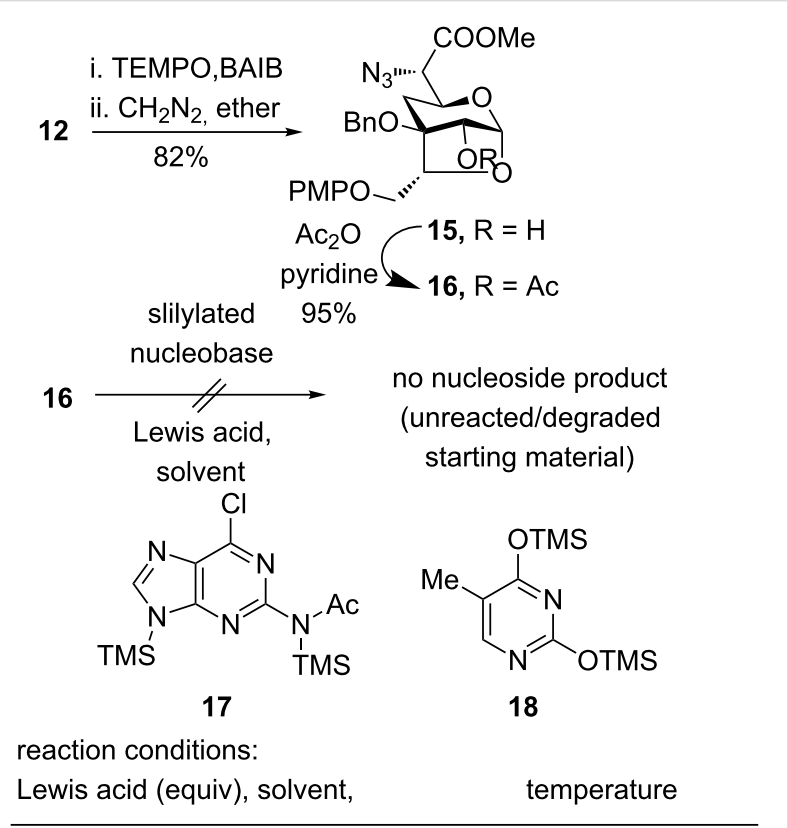

1. TMSOTf (1-5), $\mathrm{CH}_{3} \mathrm{CN} / \mathrm{DCE} 0{ }^{\circ} \mathrm{C}$ to $\mathrm{rt}, 50{ }^{\circ} \mathrm{C} / 80-120^{\circ} \mathrm{C}$

2. $\mathrm{SnCl}_{4}(1-5), \mathrm{CH}_{3} \mathrm{CN} / \mathrm{DCE} \quad 0^{\circ} \mathrm{C}$ to rt, $50{ }^{\circ} \mathrm{C} / 80-120^{\circ} \mathrm{C}$

Scheme 4: Glycosylation of 16

Knowing the fact that the glycosylation reaction is severely influenced by numerous factors including solvent, Lewis acid, and protecting groups on the nucleobase or sugar; we thought of synthesizing the peracylated anhydrosugar to alter its reactivity towards glycosylation [22]. In this regard, anhydrosugar 15 was subjected to $10 \% \mathrm{Pd} / \mathrm{C}$ and $\mathrm{Et}_{3} \mathrm{SiH}$ (for deprotection of the benzyl functionality and reduction of the azide to an amine) affording a crude product which was directly reacted with
$\mathrm{CbzCl}$ to afford compound 19 (Scheme 5). Compound 19 on reaction with ceric ammonium nitrate (deprotection of PMP ether) followed by acetyl protection of the resultant triol using $\mathrm{Ac}_{2} \mathrm{O}$ in pyridine gave triacetate derivative 20. The triacetate 20 was then subjected for glycosylation reaction under similar reaction conditions as above which failed to give the desired product.

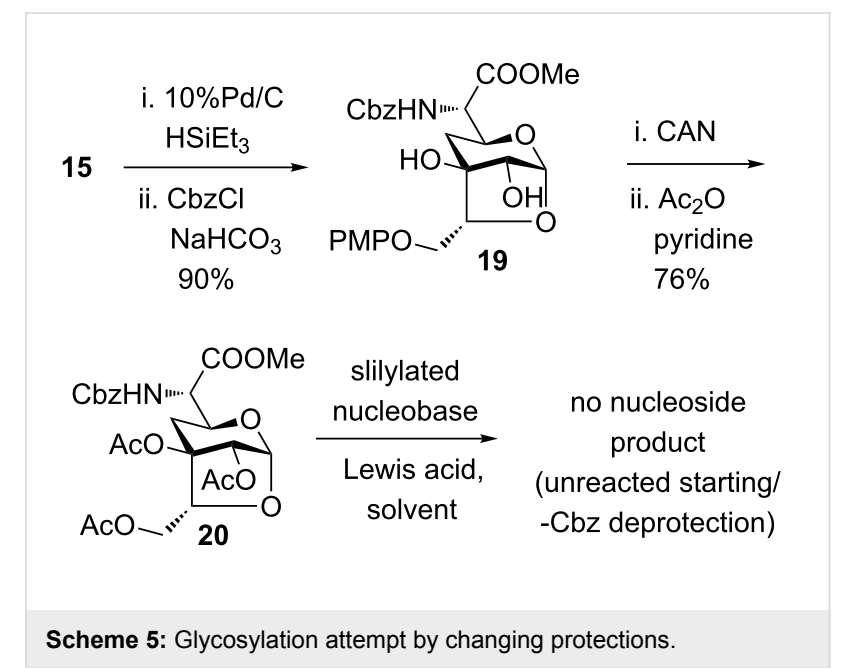

Alternatively, compound $\mathbf{1 6}$ was treated with $\mathrm{Ac}_{2} \mathrm{O}$ with a catalytic amount of $\mathrm{H}_{2} \mathrm{SO}_{4}$ that afforded pyranosyl acetate 21 as an $\alpha: \beta$ anomeric mixture (1.5:1) in good yield (Scheme 6$)$. Glycosylation of 21 with bis-silylated 2-( $N$-acetylamino)-6chloropurine under a variety of reaction conditions was found to be unsuccessful. However, glycosylation of $\mathbf{2 1}$ with bis(trimethylsilyl)thymine in the presence of TMSOTf in dichloromethane led to the stereoselective formation of $\beta$-thymine analogue 2 in $42 \%$ ( $71 \%$ based on recovered starting material) yield [23]. In the ${ }^{1} \mathrm{H}$ NMR spectrum of 2 , the large coupling constant between $\mathrm{H}^{\prime}$ ' and $\mathrm{H} 2$ ' $(J=9.4 \mathrm{~Hz})$ [5] indicated their relative diaxial orientation confirming the formation of $\beta$-glycosylated product 2 . In this reaction, the preferred attack of the 
thymine nucleobase from the $\beta$-face is being assisted by the acetoxy group at $\mathrm{C} 2$ due to neighbouring group participation [24]. The orthogonally protected thymine analogue $\mathbf{2}$ is an important intermediate and could be utilized further for the synthesis of amipurimycin $\mathbf{1}$ and its analogues for structure-activity relationship (SAR) studies.

$$
\begin{aligned}
& 16 \underset{{ }^{\circ} \mathrm{C}, 10 \mathrm{~min}}{\stackrel{\mathrm{Cat}_{2} \mathrm{O}}{\stackrel{\mathrm{H}_{2} \mathrm{SO}_{4}}{\longrightarrow}}} \\
& \text { (8) } \\
& 2
\end{aligned}
$$

Scheme 6: Synthesis of nucleoside 2.

\section{Conclusion}

In summary, we have utilized the skeleton of D-glucose-derived homoallyl alcohol $\mathbf{3}$ as a chiral podium for efficient synthesis of the $8^{\prime} R$-glycosyl amino acid core of amipurimycin. With this protocol, we have synthesized the 6' $S$ amino acid fragment of amipurimycin. Utilization of a similar protocol with azido diol 11 could be employed for the synthesis of the corresponding 6' $R$ fragment. Compound $\mathbf{2}$ is an important intermediate towards the synthesis of amipurimycin and its analogues for development of SAR and efforts in this regard are in progress.

\section{Supporting Information}

\section{Supporting Information File 1 \\ Experimental procedures. \\ [http://www.beilstein-journals.org/bjoc/content/ supplementary/1860-5397-12-165-S1.pdf]}

\section{Supporting Information File 2}

Copies of NMR spectra.

[http://www.beilstein-journals.org/bjoc/content/ supplementary/1860-5397-12-165-S2.pdf]

\section{Acknowledgements}

We are thankful to the Department of Science and Technology, New Delhi (SERB, Project File No. EMR/2014/000873) for providing financial support and the Central Instrumentation
Facility of Savitribai Phule Pune University for providing analytical support. PRM is thankful to CSIR, New Delhi for senior research fellowship. NK is thankful to Dr. D. S. Kothari fellowship (BSR/BL/14-15/0203) from the UGC, New Delhi.

\section{References}

1. Knapp, S. Chem. Rev. 1995, 95, 1859-1876. doi:10.1021/cr00038a006

2. Ichikawa, S.; Matsuda, A. Expert Opin. Ther. Pat. 2007, 17, 487-498. doi:10.1517/13543776.17.5.487

3. Harada, S.; Kishi, T. J. Antibiot. 1977, 30, 11-16. doi:10.7164/antibiotics.30.11

4. Iwasa, T.; Kishi, T.; Matsuura, K.; Wakae, O. J. Antibiot. 1977, 30, 1-10. doi:10.7164/antibiotics.30.1

5. Goto, T.; Toya, Y.; Ohgi, T.; Kondo, T. Tetrahedron Lett. 1982, 23, 1271-1274. doi:10.1016/S0040-4039(00)87080-X

6. Stauffer, C. S.; Datta, A. J. Org. Chem. 2008, 73, 4166-4174. doi:10.1021/j08004815

7. Xue, J.; Guo, Z. J. Carbohydr. Chem. 2008, 27, 51-69. doi:10.1080/07328300802030787

8. Bhaket, P.; Stauffer, C. S.; Datta, A. J. Org. Chem. 2004, 69, 8594-8601. doi:10.1021/jo048586l

9. Garner, P.; Yoo, J. U.; Sarabu, R.; Kennedy, V. O.; Youngs, W. J. Tetrahedron 1998, 54, 9303-9316. doi:10.1016/S0040-4020(98)00585-7

10. Czernecki, S.; Franco, S.; Valery, J.-M. J. Org. Chem. 1997, 62, 4845-4847. doi:10.1021/jo962266n

11. Czernecki, S.; Valery, J.-M.; Wilkens, R. Bull. Chem. Soc. Jpn. 1996, 69, 1347-1351. doi:10.1246/bcsj.69.1347

12. Rauter, A. P.; Fernandes, A. C.; Czernecki, S.; Valery, J.-M. J. Org. Chem. 1996, 61, 3594-3598. doi:10.1021/jo952220e

13. Casiraghi, G.; Colombo, L.; Rassu, G.; Spanu, P. J. Org. Chem. 1991, 56, 6523-6527. doi:10.1021/jo00023a015

14. Hara, K.; Fujimoto, H.; Sato, K.-I.; Hashimoto, H.; Yoshimura, J. Carbohydr. Res. 1987, 159, 65-79. doi:10.1016/S0008-6215(00)90006-5

15. Mane, R. S.; Ghosh, S.; Chopade, B. A.; Reiser, O.; Dhavale, D. D. J. Org. Chem. 2011, 76, 2892-2895. doi:10.1021/jo102193q

16. Sharpless, K. B. Catalytic Asymmetric Epoxidation of Allylic alcohols.. In Catalytic asymmetric synthesis; Ojima, I., Ed.; VCH Publishers: New York, 1993; pp $103 \mathrm{ff}$.

17. Xia, Q.-H.; Ge, H.-Q.; Ye, C.-P.; Liu, Z.-M.; Su, K.-X. Chem. Rev. 2005, 105, 1603-1662. doi:10.1021/cr0406458

18. Sasaki, M.; Tanino, K.; Hirai, A.; Miyashita, M. Org. Lett. 2003, 5, 1789-1791. doi:10.1021/ol034455f

19. Formation of other regio-isomer was not observed, this was confirmed by reaction of 10 with $\mathrm{NalO}_{4}$ and analyzing reaction mixture with ${ }^{1} \mathrm{H}$ NMR for aldehyde signal.

20. Compound $\mathbf{3}$ to $\mathbf{1 0}$ follows standard carbohydrate assignments (numbering). However for convenience, compound 12, 13, 14 and 16-21 follows assignments relative to amipurimycin.

21. Jackman, L. M.; Cotton, F. A., Eds. Dynamic nuclear magnetic resonance spectroscopy; Academic Press INC: London, 1975.

22. Vorbrüggen, H.; Ruh-Pohlenz, C. Org. React. 2000, 55. doi:10.1002/0471264180.or055.01

23. In the glycosylation reaction, use of acetonitrile as solvent instead of DCE has resulted in the formation of $\mathbf{1 6}$ and not the glycosylated product.

24. Vorbrüggen, H.; Höfle, G. Chem. Ber. 1981, 114, 1256-1268. doi:10.1002/cber.19811140405 


\section{License and Terms}

This is an Open Access article under the terms of the Creative Commons Attribution License

(http://creativecommons.org/licenses/by/2.0), which permits unrestricted use, distribution, and reproduction in any medium, provided the original work is properly cited.

The license is subject to the Beilstein Journal of Organic Chemistry terms and conditions:

(http://www.beilstein-journals.org/bjoc)

The definitive version of this article is the electronic one which can be found at:

doi:10.3762/bjoc. 12.165 